Check for updates

Cite this: Chem. Sci., 2019, 10, 9042

๑ All publication charges for this article have been paid for by the Royal Society of Chemistry

Received 18th July 2019

Accepted 7th August 2019

DOI: $10.1039 / c 9 s c 03560 e$

rsc.li/chemical-science

\section{Sulphide as a leaving group: highly stereoselective bromination of alkyl phenyl sulphides $\uparrow$}

\author{
Daniele Canestrari, ${ }^{a}$ Caterina Cioffi, ${ }^{a}$ Ilaria Biancofiore, ${ }^{\text {ab }}$ Stefano Lancianesi, ${ }^{a}$ \\ Lorenza Ghisu, ${ }^{a}$ Manuel Ruether, ${ }^{c}$ John O'Brien, ${ }^{c}$ Mauro F. A. Adamo (D) *a \\ and Hasim Ibrahim (1D*a
}

\begin{abstract}
A conceptionally novel nucleophilic substitution approach to synthetically important alkyl bromides is presented. Using molecular bromine $\left(\mathrm{Br}_{2}\right)$, readily available secondary benzyl and tertiary alkyl phenyl sulphides are converted into the corresponding bromides under exceptionally mild, acid- and base-free reaction conditions. This simple transformation allows the isolation of elimination sensitive benzylic $\beta$ bromo carbonyl and nitrile compounds in mostly high yields and purities. Remarkably, protic functionalities such as acids and alcohols are tolerated. Enantioenriched benzylic $\beta$-sulphido esters, readily prepared by asymmetric sulpha-Michael addition, produce the corresponding inverted bromides with high stereoselectivities, approaching complete enantiospecificity at $-40{ }^{\circ} \mathrm{C}$. Significantly, the reported benzylic $\beta$-bromo esters can be stored without racemisation for prolonged periods at $-20{ }^{\circ} \mathrm{C}$. Their synthetic potential was demonstrated by the one-pot preparation of $\gamma$-azido alcohol (S)-5 in $90 \%$ ee. NMR studies revealed an initial formation of a sulphide bromine adduct, which in turn is in equilibrium with a postulated dibromosulphurane intermediate that undergoes $\mathrm{C}-\mathrm{Br}$ bond formation.
\end{abstract}

\section{Introduction}

Alkyl bromides are versatile and extensively utilised synthetic intermediates, constitute precursors for a wide range of $\mathrm{C}-\mathrm{C}^{1}$ and $\mathrm{C}-$ heteroatom ${ }^{2}$ bond forming reactions, and are motifs found in biologically active natural products. ${ }^{3}$ Given their importance, numerous methods have been developed for their preparation, ${ }^{4}$ with protocols relying on the nucleophilic substitution of alkyl alcohols with bromide ions remaining the most widely applied and studied. ${ }^{5,6}$ Among them, the use of phosphorus(v) or phosphorus(III) reagents is particularly widespread (Scheme 1a). ${ }^{7}$ Catalytic variants of the phosphorus(v) based Appel reaction have been developed recently, ${ }^{8}$ including a catalytic system for the direct deoxybromination of alcohols. ${ }^{8 b}$ Other innovative modes for catalytic activation of alkyl alcohols towards bromide ion substitution have recently emerged; ${ }^{6 b, 9}$ however, these protocols proceed through in situ substitution of catalytically formed alkyl chloride

\footnotetext{
${ }^{a}$ Centre for Synthesis and Chemical Biology (CSCB), Department of Chemistry, Royal College of Surgeons in Ireland, 123 St. Stephen's Green, Dublin 2, Ireland. E-mail: madamo@rcsi.ie; hasimibrahim@rcsi.ie

${ }^{b}$ IRBM Science Park S.p.A, Department of Medicinal Chemistry, Via Pontina, 30.600, 00071 Pomezia RM, Italy

'Trinity Biomedical Sciences Institute, School of Chemistry, The University of Dublin, Trinity College, Dublin 2, Ireland

$\dagger$ Electronic supplementary information (ESI) available: Experimental procedures and spectroscopic characterization for all new compounds, including details of NMR experiments and racemisation study. See DOI: 10.1039/c9sc03560e
}

intermediates by added exogenous bromide ions (Finkelstein reaction). ${ }^{6 b, 9 d}$

The above methods showcase the recent progress made in the deoxybromination of alkyl alcohols; however, challenges remain such as alkene side product formation from elimination sensitive bromides, limited scope and functional group tolerance, difficulties in removing by-products such as phosphine oxides, requirement of multiple reagents and bromide racemisation from optically active alkyl alcohols. ${ }^{6 a, 10}$

We have recently reported a novel nucleophilic chlorination approach to obtaining alkyl chlorides from readily available alkyl phenyl sulphides. ${ }^{11}$ This mild and rapid (dichloroiodo) benzene $\left(\mathrm{PhICl}_{2}\right)$ promoted transformation proceeded formally via a $\mathrm{S}_{\mathrm{N}} 2$ chloride ion attack on a proposed, oxidatively generated chlorosulphonium chloride intermediate.

Considering the above-mentioned limitations in the preparation of alkyl bromides from alcohols, we posed the question whether sulphides could be used as precursors for alkyl bromides. Sulphides can be accessed by a number of methods, especially via thiol addition to widely available and inexpensive Michael acceptors. However, it was unclear if this was a viable approach, since $\mathrm{Br}_{2}$ and other $\mathrm{Br}^{+}$equivalents are weaker oxidising agents than $\mathrm{PhICl}_{2}$ (vide infra).

Herein, we delineate how the concept of 'sulphide as leaving. group' was exploited for the bromination of alkyl phenyl sulphides using $\mathrm{Br}_{2}$, an inexpensive laboratory commodity (Scheme 1b). This study culminated in the development of an 
(a) Deoxybromination of alcohols: Appel reaction

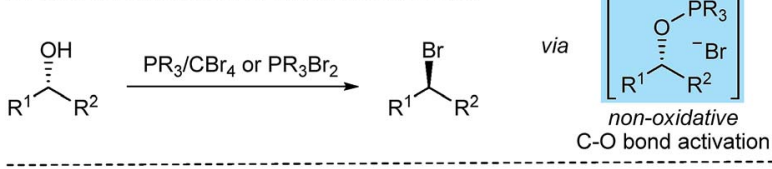

(b) This work: bromination of phenyl sulphides
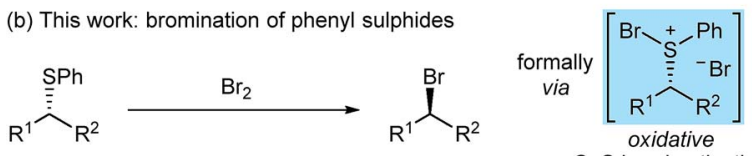

C-S bond activation

(c) Possible species arising from reaction of $\mathrm{Br}_{2}$ with sulphides

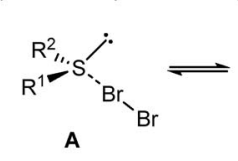<smiles>[R][Sb]([R7])(C)CC</smiles>

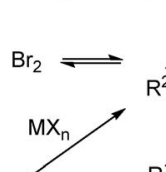

$\dddot{i}_{+}$

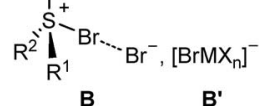

$\mathrm{R}^{1}, \mathrm{R}^{2}=$ alkyl

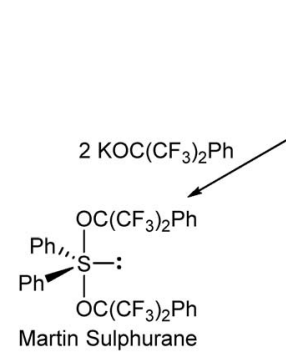

Martin Sulphurane

Scheme 1 Nucleophilic bromination of alkyl phenyl sulphides in context.

exceptionally mild, chemoselective and highly stereoselective nucleophilic bromination reaction.

The reaction of diorganosulphides with $\mathrm{Br}_{2}$ has been known for over 100 years to oxidise the sulphur(II) centre; ${ }^{12}$ however, conflicting reports on the nature of the formed species have been disclosed. Depending on sulphide substitution, temperature, methods of generation, isolation and structural analysis (i.e. in the solid state or in solution), ${ }^{\mathbf{1 3}}$ it has been suggested that the reaction could, via an equilibrium, generate tetrahedral sulphur(II) molecular complexes A (MCs), trigonal pyramidal sulphur(Iv) bromosulphonium bromides B or trigonal bipyramidal (TB) sulphur(Iv) dibromosulphurane adducts C (Scheme 1c). ${ }^{\mathbf{1 3 , 1 4}}$ NMR spectroscopic studies in support of adducts $\mathbf{A}$ and/ or $\mathbf{C}$ in solution have been reported. ${ }^{\mathbf{1 5}}$

In the case of dialkyl substitution, the treatment of bromine adducts with Lewis acidic metal halides $\left(\mathrm{MX}_{n}\right)$ was reported to form bromosulphonium $\left[\mathrm{BrMX}_{n}\right]$ salts $\mathbf{B}^{\prime}$ by irreversible bromide ion complexation. ${ }^{\mathbf{1 3 b}, \mathbf{1 4 c}, \mathbf{1 6}}$ These salts have found widespread application in organic synthesis as, for example, bromonium ion $\left(\mathrm{Br}^{+}\right)$equivalents and/or oxidants. ${ }^{16,17}$ Dibromosulphuranes $\mathbf{C}$ have been proposed as intermediates in several transformations. For instance, in his seminal work on organosulphuranes, Martin employed dibromosulphuranes as intermediates en route to alkoxysulphuranes, ${ }^{\mathbf{1 8}}$ such as the versatile Martin sulphurane reagent. ${ }^{19}$ These reactions proceed via alkoxide displacement of the apical bromide ligands. In a related transformation, sulphuranes $\mathbf{C}$ were converted into the corresponding sulphoxides upon treatment with water and a base (Scheme 1c). ${ }^{20}$ However, that dibromosulphurane intermediates could reductively collapse to form concurrently alkyl bromides and organosulphenyl bromides has to the best of our knowledge, not been reported. Herein, we show that, with the right choice of the substituents on the sulphur, such a transformation is indeed feasible, and in doing so uncover that aryl sulphides can be considered a valuable, heretofore unexplored leaving group for highly stereoselective, nonneighbouring group assisted, nucleophilic bromination.

\section{Results and discussion}

As part of our studies on desulphurative chlorination with $\mathrm{PhICl}_{2}$, we examined the ability of other electrophilic chlorinating reagents, and specifically that of elemental chlorine, to promote chlorination of $\beta$-sulphido esters. In a preliminary experiment, we treated $\beta$-sulphido ester $\mathbf{1 a}$ with $\mathrm{Cl}_{2}$ gas and observed a rapid consumption of the starting material within 3 minutes. ${ }^{1} \mathrm{H}$ NMR analysis of the crude material showed the formation of $\beta$-chloro ester $\mathbf{2 a}$ as the major product, accompanied by dehydrochlorination-derived methyl cinnamate (3a) in a ratio of $70: 30$ (Scheme 2). In spite of significant alkene sideproduct formation, this experiment clearly demonstrated that molecular chlorine could promote desulphurative chlorination. This reactivity formed the basis for our efforts to examine elemental bromine in the desulphurative bromination of $\beta$ sulphido esters.

In an initial experiment, adding 1.0 equivalent of neat $\mathrm{Br}_{2}$ to our test substrate $\beta$-sulphido ester 1a in dry dichloromethane and monitoring the progress of the reaction by ${ }^{1} \mathrm{H}$ NMR spectroscopy showed, within 15 minutes, complete conversion to $\beta$ bromo ester 4a, accompanied by small amounts of dehydrobromination-derived methyl cinnamate (3a) (Table 1, entry 1). This experiment clearly indicated that $\mathrm{Br}_{2}$ could not only promote bromination of sulphide 1a, but also, gratifyingly, with very little alkene side-product formation. Moreover, this surprising outcome was even more profound when considering the large difference in oxidising power between $\mathrm{Cl}_{2}$ and $\mathrm{Br}_{2}$.

To simplify the procedure and ensure accurate addition of $\mathrm{Br}_{2}$, we repeated this reaction with a $1.0 \mathrm{M}$ solution of $\mathrm{Br}_{2}$ in dry DCM, which gave complete conversion to the brominated product in 25 minutes, and significantly, without the formation of alkene 3a (entry 2). We were delighted to isolate $\beta$-bromo ester $4 \mathrm{a}$ in an excellent yield of $95 \%$ after $\mathrm{SiO}_{2}$ chromatography. Performing the same reaction in non-purified DCM gave complete conversion in a shorter reaction time of $15 \mathrm{~min}$ but with small amounts of alkene 3a (entry 3 ). The reaction proceeded equally well in toluene or dichloroethane (DCE), albeit with slightly longer reaction times (entries 4 and 5), whereas THF as solvent gave a complex mixture (entry 6). A marked increase in the reaction rate was observed in MeCN; however,

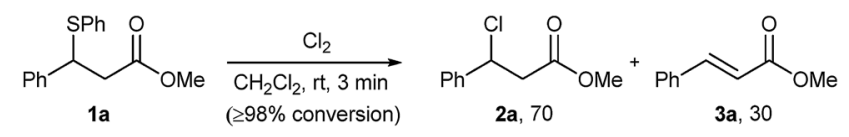

Scheme 2 Reaction of $\beta$-sulphido ester 1a with $\mathrm{Cl}_{2}$. 
Table 1 Optimisation of reaction conditions with sulphide $1 a^{a, b}$

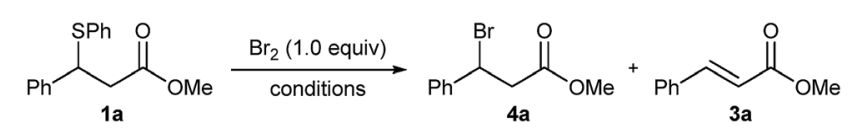

\begin{tabular}{lllll}
\hline Entry & Solvent & Temp $\left({ }^{\circ} \mathrm{C}\right)$ & Time $^{c}(\min )$ & Ratio ${ }^{d} \mathbf{4 a}: \mathbf{3 a}$ \\
\hline $1^{e}$ & $\mathrm{CH}_{2} \mathrm{Cl}_{2}$ & $\mathrm{rt}$ & 15 & $98: 2$ \\
2 & $\mathrm{CH}_{2} \mathrm{Cl}_{2}{ }^{g}$ & $\mathrm{rt}$ & 25 & $100: 0(95)^{f}$ \\
3 & $\mathrm{CH}_{2} \mathrm{Cl}_{2}{ }^{g}$ & $\mathrm{rt}$ & 15 & $98: 2$ \\
4 & Toluene & $\mathrm{rt}$ & 30 & $100: 0$ \\
5 & $\mathrm{DCE}$ & $\mathrm{rt}$ & 30 & $98: 2$ \\
6 & $\mathrm{THF}$ & $\mathrm{rt}$ & 90 & $\mathrm{CM}$ \\
7 & $\mathrm{MeCN}$ & $\mathrm{rt}$ & 5 & $99: 1(72)^{f}$ \\
8 & $\mathrm{CH}_{2} \mathrm{Cl}_{2}$ & 0 & 60 & $100: 0$ \\
9 & $\mathrm{CH}_{2} \mathrm{Cl}_{2}$ & -20 & 180 & $100: 0$ \\
10 & $\mathrm{CH}_{2} \mathrm{Cl}_{2}$ & -40 & 900 & $100: 0$
\end{tabular}

${ }^{a}$ Conditions: $1 \mathrm{a}(0.5 \mathrm{mmol}), \mathrm{Br}_{2}(0.5 \mathrm{mmol})$ as $1.0 \mathrm{M}$ solution in reaction solvent, and dry solvent $(3.0 \mathrm{~mL}, 0.17 \mathrm{M})$; all reactions proceeded to complete conversion $(\geq 98 \%) .{ }^{b}$ Styrene $(0.65 \mathrm{mmol}, 1.3$ equiv.) was added to quench the reaction. ${ }^{c}$ Reaction progress was monitored by ${ }^{1} \mathrm{H}$ NMR spectroscopy using a stock solution of styrene in $\mathrm{CDCl}_{3}(0.03 \mathrm{M}) .{ }^{d}$ Determined by ${ }^{1} \mathrm{H}$ NMR spectroscopy of the crude material. ${ }^{e}$ Neat $\mathrm{Br}_{2}(0.5 \mathrm{mmol})$ used. ${ }^{f}$ Isolated yield after $\mathrm{SiO}_{2}$ chromatography. ${ }^{g}$ Non-purified $\mathrm{CH}_{2} \mathrm{Cl}_{2}$. $\mathrm{CM}=$ complex mixture.

workup and purification gave bromo ester $\mathbf{4 a}$ in a lower yield of $72 \%$ (entry 7 ).

Conducting the reaction in DCM at lower temperatures resulted in longer reaction times but gave clean conversions to bromide $4 \mathrm{a}$, with the reaction at $-40{ }^{\circ} \mathrm{C}$ requiring 15 hours for completion (entries 8-10). This is in stark contrast to desulphurative chlorination with $\mathrm{PhICl}_{2}$, which showed an increase in alkene side-product formation upon lowering the reaction temperature to $0{ }^{\circ} \mathbf{C} .{ }^{\mathbf{1 1}}$ Moreover, in contrast with the limited solubility of $\mathrm{PhICl}_{2}$ in chlorinated solvents at lower temperatures, ${ }^{21}$ reactions with $\mathrm{Br}_{2}$ remained homogeneous throughout. Crucially, in all of the above reactions only small amounts or no dehydrobrominated alkene 3 a was observed, ${ }^{22}$ which is a testament to the exceptionally mild, base- and acid-free reaction conditions.

Using conditions from entry 2 in Table 1 we proceeded to examine the scope of our bromination with various $\beta$-sulphido carbonyl compounds, which generally gave good to excellent yields of the corresponding bromide products (Table 2, 4a-4p). Reaction times varied with substitution on the aryl ring, with aryl groups having deactivating substituents requiring longer reaction times ( 4 hours for 1f). Bromination of slow-reacting sulphides could be accelerated by running the reaction at double the concentration in DCM (1e), or in DCE as solvent at $50{ }^{\circ} \mathrm{C}$ ( $1 \mathrm{~g}$ and 1i). Both heating at $50{ }^{\circ} \mathrm{C}$ and excess of $\mathrm{Br}_{2}$ were needed for the bromination of sulphides $\mathbf{1 h}$ and $\mathbf{1 0}$.

Remarkably, desulphurative bromination also occurred with substrates having protic functionalities such as $\beta$-sulphido acids $1 \mathrm{n}$ and 10 and sulphido alcohols $\mathbf{1 t}$ and $\mathbf{1 u}$, a transformation that would be incompatible with the use of the aforementioned phosphorus(v) or phosphorus(III) based
Table 2 Scope for the bromination of phenyl sulphides $1^{a, b}$

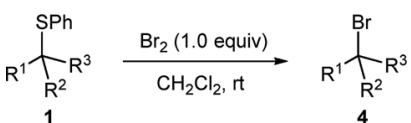
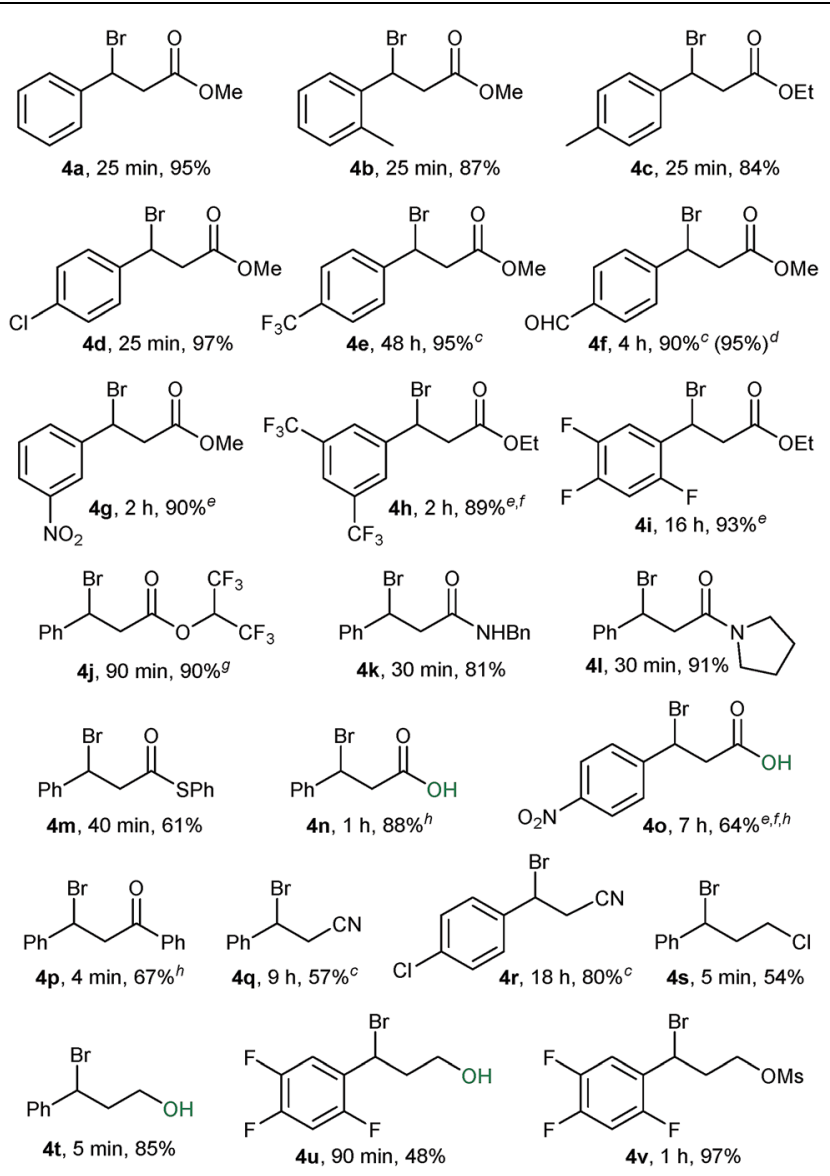<smiles>COCCC(Br)c1cccs1</smiles>

$4 \mathrm{w}, 25 \mathrm{~min}, 50 \%^{i}$<smiles>Brc1ccc(C(Br)c2ccccc2)cc1</smiles><smiles>CC(C)C1C2CC3CC1CC(Br)(C3)C2</smiles><smiles>[R]CCC(C)(C)Br</smiles>

$4 z a, R=P h, 30 \mathrm{~min}, 51 \%$ 4zb, R = OTs, $24 \mathrm{~h}, 30 \%^{k}$
${ }^{a}$ Unless otherwise stated, reactions were performed on a $0.5 \mathrm{mmol}$ scale at $0.17 \mathrm{M}(3 \mathrm{~mL})$ using $0.5 \mathrm{mmol}$ of $\mathrm{Br}_{2}$ as $1.0 \mathrm{M}$ solution in $\mathrm{CH}_{2} \mathrm{Cl}_{2}$; reaction progress was monitored by ${ }^{1} \mathrm{H}$ NMR using a stock solution of styrene in $\mathrm{CDCl}_{3}(0.03 \mathrm{M}) .{ }^{b}$ Isolated yield after $\mathrm{SiO}_{2}$ chromatography. ${ }^{c}$ Run at $0.33 \mathrm{M}(1.5 \mathrm{~mL}) .{ }^{d} 5.0 \mathrm{mmol}$ scale. ${ }^{e}$ Reaction performed in DCE at $50{ }^{\circ} \mathrm{C} .{ }^{f}$ Run with $1.0 \mathrm{mmol}$ (2.0 equiv.) of $\mathrm{Br}_{2} .{ }^{g}$ Contains $8 \%$ alkene. ${ }^{h}$ Isolated yield after trituration or recrystallisation. ${ }^{i}$ Yield of the corresponding trifluoroethyl ether derivative. ${ }^{j}{ }^{1} \mathrm{H}$ NMR yield using $\mathrm{CH}_{2} \mathrm{Br}_{2}$ as the internal standard. ${ }^{k}$ Isolated yield contains $26 \% 3,4$ dibromide side-product.

deoxybrominating reagents. The chemoselectivity for sulphido alcohols $\mathbf{1 t}$ and $\mathbf{1 u}$ is even more striking, when considering that the productive intermediate is formally a bromosulphonium ion analogous to the one generated in Swern oxidation. These brominations proceeded to complete conversion, with bromo alcohol 4t obtained in a high $85 \%$ yield. Bromo alcohol $4 \mathbf{u}$ was isolated in a moderate yield after purification; nevertheless, it could be generated in situ and taken further in a follow-up 
reaction. For instance, a one-pot bromination/mesylation sequence of sulphido alcohol $1 \mathbf{u}$ gave bromo mesylate $\mathbf{4 v}$ in $45 \%$ yield ( $97 \%$ yield from sulphide $1 \mathbf{v}$ ).

Performing the bromination on easily accessible $\beta$-sulphido nitriles $1 \mathbf{q}$ and $1 \mathbf{r}$ gave rise to the corresponding $\beta$-bromonitriles in fair to good yields. Our method provides a direct and simple route to these novel and potentially versatile compounds, ${ }^{23}$ especially when considering that the only direct literatureknown method relies on the mostly low-yielding halodehydration of the corresponding alcohol precursors. ${ }^{24}$

Scale-up of the above reactions proceeded without problems. For instance, a ten-fold scale-up, at $5 \mathrm{mmol}$, of the bromination of sulphide $\mathbf{1 f}$ gave bromide $\mathbf{4 f}$ in an excellent $95 \%$ yield, thus underlining the practicality of the herein reported bromination protocol.

Bromination of sulphides containing electron-rich heteroarenes such as sulphido thiophene $1 \mathrm{w}$ proceeded to complete conversion; however, attempts to purify the corresponding bromide $4 \mathbf{w}$ by chromatography resulted in decomposition. Ultimately, 2,2,2-trifluoroethanol solvolysis afforded the 2,2,2trifluoroethoxy derivative 4wa in $50 \%$ yield (see the ESI $\dagger$ ). Likewise, bromide $\mathbf{4 x}$ was sensitive towards purification by chromatography and was isolated as the 2,2,2-trifluoroethoxy derivative $4 \mathbf{x a}$ in $78 \%$ yield.

Initial experiments with adamantyl sulphide $\mathbf{1 y}$ indicated that tertiary alkyl sulphides were suitable substrates. Bromination of sulphide $1 \mathbf{y}$ proceeded with clean complete conversion as indicated by the ${ }^{1} \mathrm{H}$ NMR spectrum of the crude material. However, the moderate yield of $68 \%$ for bromide $4 y$ (as well as for $4 \mathbf{4 s}$ ) was due to the chromatographic separation from $(\mathrm{PhS})_{2}$, which possessed similar polarity. Bromination of tertiary dimethylalkyl-derived sulphides proceeded to complete conversion, but was accompanied by elimination side-products. Thus, sulphide 1za gave within $30 \mathrm{~min}$ the corresponding bromide in $51 \%{ }^{1} \mathrm{H}$ NMR yield together with minor elimination side-products, whereas bromo tosylate $\mathbf{4 z b}$ could be isolated in $30 \%$ yield as an inseparable $3: 1$ mixture together with its corresponding $\mathrm{Br}_{2}$ alkene addition side-product (see the ESI $\dagger$ ).

\section{Optically active bromides}

There are relatively few methods to access optically active, racemisation-sensitive benzylic bromides. By far the most widely applied methods rely on nucleophilic $\mathrm{S}_{\mathrm{N}} 2$ bromination of optically active benzylic alcohols; however, these reactions require accurate monitoring of reaction conditions and usually yield partially racemised bromide products. Potentially very useful, but rare, asymmetric protocols for obtaining benzylic bromides are emerging. These include the recently reported $\mathrm{Rh}-$ catalysed asymmetric Kharasch addition to styrenes, ${ }^{25}$ and the Cu-catalysed formal asymmetric hydrobromination of styrenes. ${ }^{26}$ However, these methods require the use of precious metal-chiral phosphine catalysis and display limited substrate scope.

Given the exceptionally mild reaction conditions to access elimination-sensitive bromides, we proceeded to examine the suitability of our method for the synthesis of highly versatile

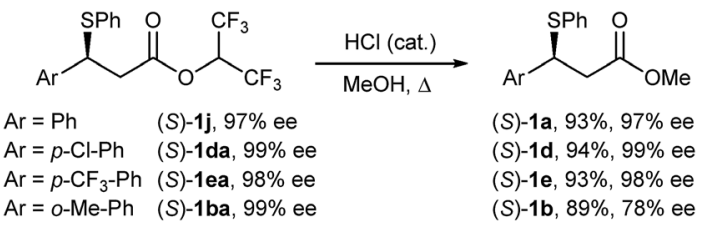

Scheme 3 Synthesis of enantiomerically enriched $\beta$-sulphido methyl esters.

optically active benzylic $\beta$-bromo esters from enantiomerically enriched benzylic $\beta$-sulphido esters. Sulphide substrates were prepared according to Wang's asymmetric sulpha-Michael addition of thiophenol to hexafluoroisopropyl cinnamates. ${ }^{27}$ As the bromination of $\beta$-sulphido hexafluoroisopropyl esters $\mathbf{1} \mathbf{j}$ and 1ea gave, after purification by chromatography, bromides containing $8 \%$ and $25 \%$ alkene, respectively, we decided to investigate the corresponding $\beta$-sulphido methyl esters. Thus, acid-catalysed methanolysis was achieved without erosion of the enantiomeric purity for sulphides $(S)-\mathbf{1 j},(S)-\mathbf{1 d a}$ and $(S)-\mathbf{1 e a}$ (Scheme 3). However, methanolysis of sulphido ester (S)-1ba having $99 \%$ ee gave, under the studied conditions, partially racemised $(S)-\mathbf{1 b}$ in $\mathbf{7 8 \%}$ ee.

Subjecting sulphide $(S)$-1a to the optimised bromination at room temperature (Table 1, entry 2) gave inverted bromide $(R)$ 4a in $83 \%$ ee and $86 \%$ es (Table 3 , entry 1 ), which was subsequently confirmed to have an $R$ absolute configuration (vide infra). We were delighted to find that lowering the reaction temperature had a significant effect on the enantioselectivity of the reaction (Table 3, entries 2-4), with the bromination ran at $-40{ }^{\circ} \mathrm{C}$ affording, after 15 hours, bromide $(R)-4 \mathrm{a}$ in an excellent $93 \%$ ee and $96 \%$ es. Similarly, bromination of sulphide $(S)-\mathbf{1 d}$ at $-40{ }^{\circ} \mathrm{C}$ gave bromide $(R)-4 \mathrm{~d}$ in $93 \%$ ee and $94 \%$ es (entry 5 ). ${ }^{28}$ The slow reacting sulphide $(S)$-1e gave at room temperature bromide $(R)-4 e$ in high $86 \%$ ee and $88 \%$ es (entry 6). Lowering the reaction temperature to $0{ }^{\circ} \mathrm{C}$ gave bromide $(R)-4 \mathbf{e}$ with a slightly improved enantiomeric excess of $87 \%$, but at the expense of a significant drop in the reaction rate (entry 7 ). Finally, running sulphide $(S)-\mathbf{1 b}$ having $78 \%$ ee at $-40{ }^{\circ} \mathrm{C}$ gave bromide $(R)-4 \mathbf{b}$ in $66 \%$ ee, which still corresponded to $85 \%$ es, showing that the reaction tolerated sterically encumbered orthosubstituted aryl groups (entry 8).

Optically active benzylic bromides have been reported to be prone to racemisation. ${ }^{1 c, e, 10}$ For instance, a sample of $(R)-1$ (bromoethyl)benzene having $88 \%$ ee kept at $0{ }^{\circ} \mathrm{C}$ was shown to fully racemise within 8 hours. ${ }^{1 c}$ We therefore monitored the configurational stability of a sample of $\beta$-bromo ester $(R)$-4a having $93 \%$ ee over a three-month period at $-20{ }^{\circ} \mathrm{C}$ and room temperature, and uncovered that when stored at $-20{ }^{\circ} \mathrm{C}$, no racemisation was detectable. In contrast, the sample stored at room temperature showed partial racemisation with a drop in enantiomeric excess to $78 \%$ after the same period (see the ESI $\dagger$ for further information). This is a very significant finding as it shows that optically active benzylic $\beta$-bromo esters can be conveniently prepared using our method and stored for prolonged periods at $-20{ }^{\circ} \mathrm{C}$ (for at least three months) without measurable racemisation. 
Table 3 Bromination of enantiomerically enriched $\beta$-sulphido esters $^{a, b}$

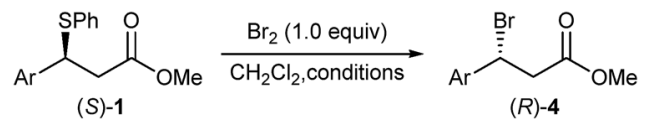

\begin{tabular}{lllllll} 
Ent. & $(S)-\mathbf{1}$ & Temp. $\left({ }^{\circ} \mathrm{C}\right)$ & Time $^{c}$ & $(R)-\mathbf{4}$ yield $^{d}(\%)$ & ee $^{e}(\%)$ & es $(\%)$ \\
\hline 1 & $(S)-\mathbf{1 a}$ & rt & $25 \mathrm{~min}$ & 82 & 83 & 86 \\
2 & $(S)-\mathbf{1 a}$ & 0 & $1 \mathrm{~h}$ & 94 & 87 & 90 \\
3 & $(S)-\mathbf{1 a}$ & -20 & $3 \mathrm{~h}$ & 87 & 92 & 95 \\
4 & $(S)-\mathbf{1 a}$ & -40 & $15 \mathrm{~h}$ & 89 & 93 & 96 \\
5 & $(S)-\mathbf{1 d}$ & -40 & $24 \mathrm{~h}$ & 97 & 93 & 94 \\
6 & $(S)-\mathbf{1 e}$ & $\mathrm{rt}$ & $48 \mathrm{~h}$ & 95 & 86 & 88 \\
7 & $(S)-\mathbf{1 e}$ & 0 & $48 \mathrm{~h}$ & 36 & 87 & 89 \\
8 & $(S)-\mathbf{1 b}$ & -40 & $15 \mathrm{~h}$ & 99 & 66 & 85
\end{tabular}

${ }^{a}$ Conditions: $(S)-1(0.25 \mathrm{mmol}), \mathrm{Br}_{2}(0.25 \mathrm{mmol})$ as $1.0 \mathrm{M}$ solution in $\mathrm{CH}_{2} \mathrm{Cl}_{2}$, and dry $\mathrm{CH}_{2} \mathrm{Cl}_{2}(1.5 \mathrm{~mL}, 0.17 \mathrm{M}) .{ }^{b}$ Styrene $(0.3 \mathrm{mmol}, 1.3$ equiv.) was added to quench the reaction. ${ }^{c}$ Reaction progress was monitored by ${ }^{1} \mathrm{H}$ NMR spectroscopy using a stock solution of styrene in $\mathrm{CDCl}_{3}(0.03 \mathrm{M}) .{ }^{d}$ Isolated yield after $\mathrm{SiO}_{2}$ chromatography. ${ }^{e}$ ee values were determined by HPLC analysis on the chiral stationary phase.

In order to demonstrate the versatility of our enantiomerically enriched $\beta$-bromo esters and to corroborate that the desulphurative bromination occurred with the proposed inversion of configuration, we converted bromo ester $(R)-\mathbf{4 a}$ in a reduction/azidation sequence into azido alcohol $(S)$-5 (Scheme 4). After examining several reducing reagents, we discovered that DIBAL readily reduced the ester functionality in the presence of a benzylic bromide to afford bromo alcohol $(R)-4 t$ in an excellent $93 \%$ yield, but with a partially eroded optical purity of $83 \%$ ee (Scheme 4 ). We believe that this is due to the propensity of optically active bromo alcohol $(R)-4 t$ towards racemisation. ${ }^{29}$ Subsequent treatment of the crude product with sodium azide in DMF gave azido alcohol $(S)-5$ in $86 \%$ yield and $83 \%$ ee.

Given that bromo alcohol $(R)-\mathbf{4 t}$ is racemisation sensitive, we devised an alternative one-pot protocol by submitting the in situ generated bromo aluminium alcoholate $(R)-6$ to sodium azide substitution and were delighted to obtain azido alcohol $(S)-5$ in

$$
\underbrace{\text { Two-Pot }}_{(R)-4 a, 93 \% \text { ee }} \underset{(93 \%)}{\stackrel{\mathrm{DIBAL}}{\longrightarrow}}
$$

One-Pot
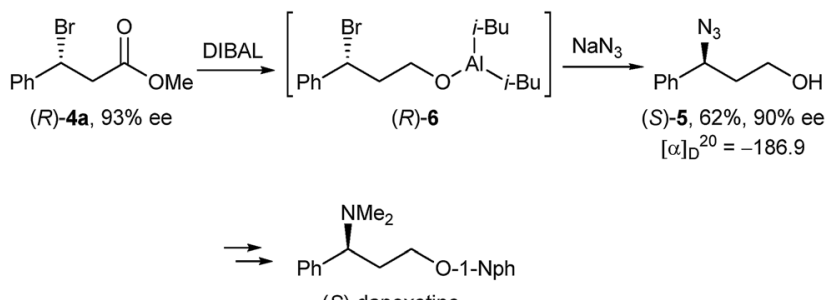

$$
\text { (S)-dapoxetine }
$$

Scheme 4 Preparation of enantiomerically enriched azido alcohol (S)5.
$62 \%$ yield and $90 \%$ ee. Comparing the sign of the specific optical rotation with that of the literature-known azido alcohol $(R)-5^{30}$ confirmed that bromide 4 a was formed with an $R$ absolute configuration and $\mathrm{S}_{\mathrm{N}} 2$ inversion from sulphide $(S)$-1a. Azido alcohol $(S)-5$ can be considered an advanced intermediate en route to $(S)$-dapoxetine, ${ }^{31}$ thus showcasing that the herein described optically active $\beta$-bromo esters can serve as valuable intermediates in the transition metal free synthesis of a host of APIs having a benzylic chiral centre.

\section{NMR study and mechanism}

As outlined in the Introduction, there is uncertainty surrounding the nature of the interaction of $\mathrm{Br}_{2}$ with sulphides, with very few studies reported in solution. In order to gain insight into the mechanism operating in the presented desulphurative bromination, we conducted a series of NMR experiments. They were undertaken in light of the fact that the reaction of both $\mathrm{PhICl}_{2}{ }^{32}$ and $\mathrm{Cl}_{2}{ }^{15 b, 33}$ with sulphides leads to the oxidation of the sulphur(II) centre to sulphur(Iv) forming dichlorosulphuranes.

In an initial experiment ran at an identical concentration to the actual reaction, we treated a $0.17 \mathrm{M}$ solution of sulphide $1 \mathrm{a}$ in $\mathrm{CD}_{2} \mathrm{Cl}_{2}$ pre-cooled to $-20{ }^{\circ} \mathrm{C}$ with 1.0 equivalent of a $1.0 \mathrm{M}$ solution of $\mathrm{Br}_{2}$ in $\mathrm{CD}_{2} \mathrm{Cl}_{2}$ and monitored the progress of the reaction by ${ }^{1} \mathrm{H}$ NMR spectroscopy at $-20{ }^{\circ} \mathrm{C}$ (Fig. 1). After one minute of $\mathrm{Br}_{2}$ addition, and focusing on the benzylic proton, the recorded spectrum showed the total absence of the benzylic signal of sulphide 1a at $4.67 \mathrm{ppm}$ with two new species appearing as double doublets at $5.43 \mathrm{ppm}$ and $4.84 \mathrm{ppm}$ in a ratio of $84: 16$. The major species was identified as bromo ester 4a, with the minor unknown species converting to bromide 4a upon further monitoring (Fig. 1). It was apparent that the new unknown species - postulated as being a sulphide bromine adduct intermediate $\mathbf{1 a} \cdot \mathrm{Br}_{2}$ (vide infra) - converted rapidly to bromo ester $4 \mathrm{a}$, even at $-20{ }^{\circ} \mathrm{C}$.

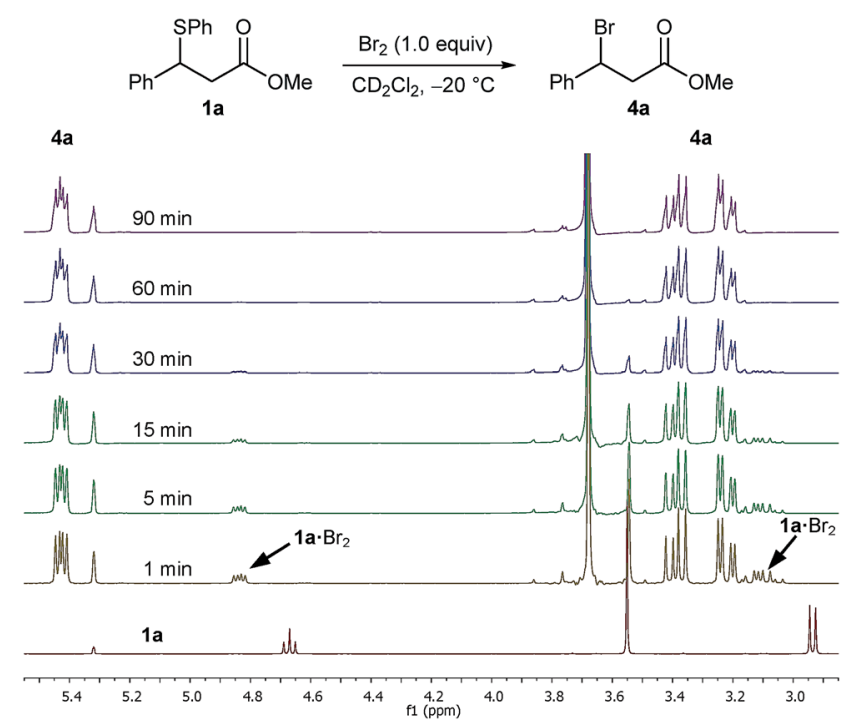

Fig. $1{ }^{1} \mathrm{H}$ NMR spectra $(400 \mathrm{MHz})$ of the reaction of $\mathrm{Br}_{2}(1.0 \mathrm{M})$ with sulphide $1 \mathrm{a}(0.17 \mathrm{M})$ in $\mathrm{CD}_{2} \mathrm{Cl}_{2}$ at $-20{ }^{\circ} \mathrm{C}$ over a period of $90 \mathrm{~min}$. 


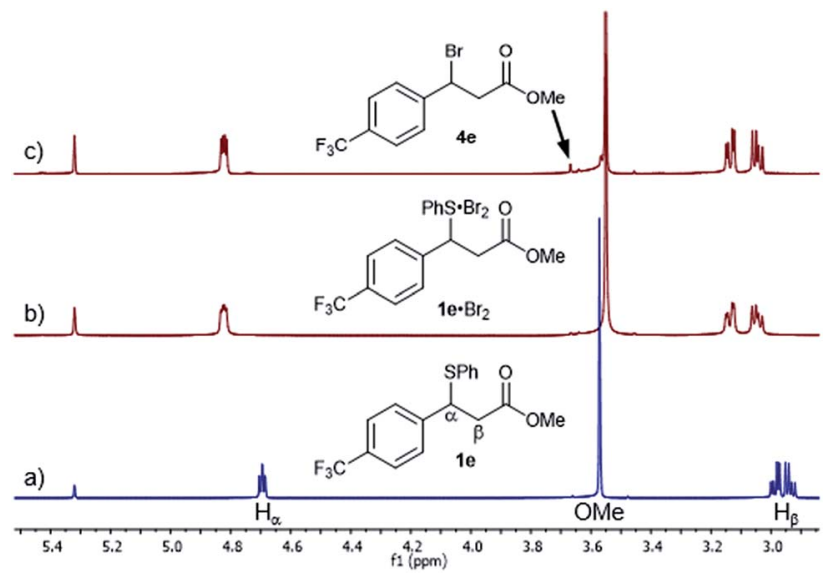

Fig. $2{ }^{1} \mathrm{H}$ NMR spectra $(800 \mathrm{MHz})$ of the $\mathrm{Br}_{2}(1.0 \mathrm{M})$ addition to sulphide $1 \mathrm{e}(0.17 \mathrm{M})$ in $\mathrm{CD}_{2} \mathrm{Cl}_{2}$ at $-20{ }^{\circ} \mathrm{C}$ : (a) sulphide $1 \mathrm{e}$ at $-20{ }^{\circ} \mathrm{C}$ before $\mathrm{Br}_{2}$ addition, (b) 2 minutes after $\mathrm{Br}_{2}$ addition and formation of the $1 \mathrm{e} \cdot \mathrm{Br}_{2}$ adduct and (c) 1 hour after $\mathrm{Br}_{2}$ addition showing the appearance of bromide $4 \mathrm{e}$.

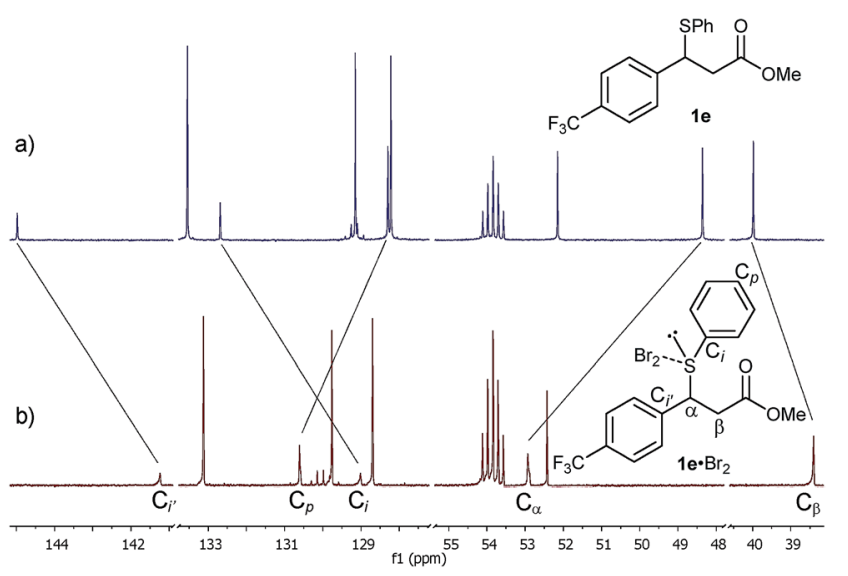

Fig. $3{ }^{13} \mathrm{C}$ NMR spectra $(201 \mathrm{MHz})$ of the $\mathrm{Br}_{2}(1.0 \mathrm{M})$ addition to sulphide 1e $(0.17 \mathrm{M})$ in $\mathrm{CD}_{2} \mathrm{Cl}_{2}$ at $-20{ }^{\circ} \mathrm{C}$ : (a) sulphide $1 \mathrm{e}$ at $-20{ }^{\circ} \mathrm{C}$ before $\mathrm{Br}_{2}$ addition and (b) after $\mathrm{Br}_{2}$ addition, displaying significant shifts of the formed $1 \mathrm{e} \cdot \mathrm{Br}_{2}$ adduct.

Given the high rate of bromination for 1a, we turned our attention to the slow-reacting sulphide 1e (Fig. 2). Thus, adding a $1.0 \mathrm{M}$ solution of $\mathrm{Br}_{2}$ in $\mathrm{CD}_{2} \mathrm{Cl}_{2}$ to a pre-cooled $0.17 \mathrm{M}$ solution of sulphide 1e and recording a ${ }^{1} \mathrm{H}$ NMR spectrum at $-20{ }^{\circ} \mathrm{C}$ showed, after $2 \mathrm{~min}$, the complete disappearance of $\mathbf{1 e}$ and its conversion to a single new species, identified by the complete disappearance of the benzylic proton signal at $4.69 \mathrm{ppm}$ and the appearance of a new double doublet at 4.82 ppm (Fig. 2b). Other significant shifts included downfield shifts of the diastereotopic $\mathrm{H}_{\beta}$ hydrogen atoms at 2.94 and $2.99 \mathrm{ppm}$ to 3.05 and $3.14 \mathrm{ppm}$, respectively, and a downfield shift of the signal of hydrogens ortho to the sulphur by 0.14 ppm (not shown).

Gratifyingly, the new species was sufficiently stable at $-20{ }^{\circ} \mathrm{C}$ to allow its full characterisation by $1 \mathrm{D}$ and $2 \mathrm{D}$ NMR

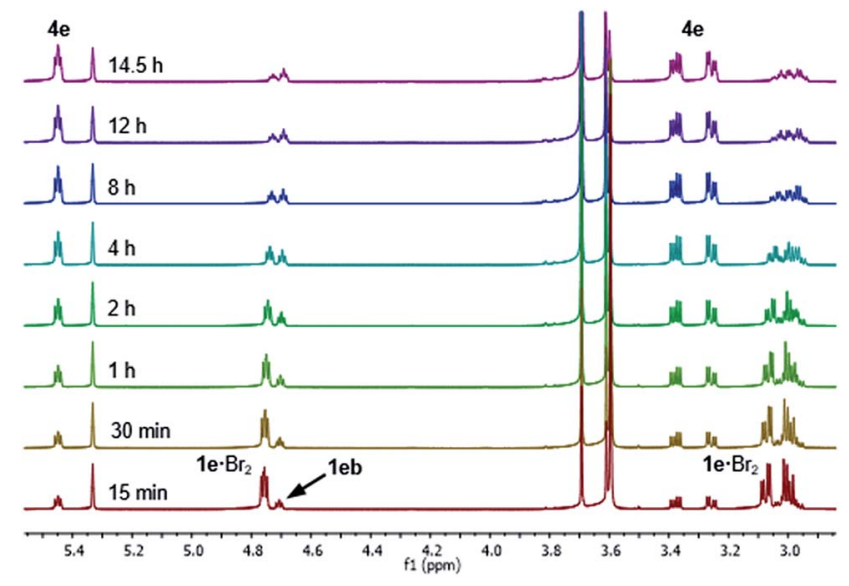

Fig. $4{ }^{1} \mathrm{H}$ NMR spectra $(800 \mathrm{MHz})$ of the $\mathrm{Br}_{2}(1.0 \mathrm{M})$ addition to sulphide $1 \mathrm{e}(0.17 \mathrm{M})$ in $\mathrm{CD}_{2} \mathrm{Cl}_{2}$ after raising the temperature to $20^{\circ} \mathrm{C}$, showing the progressive conversion of the $1 \mathrm{e} \cdot \mathrm{Br}_{2}$ adduct into bromide $4 \mathrm{e}$ and the presence of side product sulphide $1 \mathrm{eb}$.

spectroscopy. The ${ }^{13} \mathrm{C}$ NMR spectrum showed significant shifts of signals compared to 1e (Fig. 3). These included large shifts for carbons flanking the sulphur atom corresponding to an upfield shift of the resonance of the $\mathrm{C}_{\mathrm{i}}$ of $1 \mathrm{e}$ to $129.0 \mathrm{ppm}(\Delta \delta=$ $-3.7 \mathrm{ppm}$ ) and a downfield shift of the benzylic carbon $\mathrm{C}_{\alpha}$ to $52.9 \mathrm{ppm}(\Delta \delta=+4.6 \mathrm{ppm})$, as well as an upfield shift for $\mathrm{C}_{\mathrm{i}^{\prime}}$ to $141.2 \mathrm{ppm}(\Delta \delta=-3.7 \mathrm{ppm})$ (Fig. 3b). In addition, notable shifts were observed for $\mathrm{C}_{\mathrm{p}}$ of $1 \mathrm{e}$ to $130.6 \mathrm{ppm}(\Delta \delta=+2.3 \mathrm{ppm})$ and $\mathrm{C}_{\beta}$ to $38.4 \mathrm{ppm}(\Delta \delta=-1.6 \mathrm{ppm})$.

All of the above ${ }^{1} \mathrm{H}$ and ${ }^{13} \mathrm{C}$ NMR $\Delta \delta$ s are less pronounced at $20{ }^{\circ} \mathrm{C}^{15 a}$ Hence, taking into account the NMR spectroscopic criteria proposed by Nakanishi to distinguish between MCs and TBs of $\mathrm{R}^{1} \mathrm{R}^{2} \mathrm{~S} \cdot \mathrm{X}_{2}$ adducts in solution, ${ }^{15 b}$ the observed shifts most notably the upfield shift of $\mathrm{C}_{\mathrm{i}}$ of the $\mathrm{SPh}$ group - are generally consistent in terms of magnitude, direction and temperature behaviour with the presence of a $\mathrm{MC}$ structure for the $1 \mathrm{e} \cdot \mathrm{Br}_{2}$ adduct. ${ }^{15 a}$ These findings provide, to the best of our knowledge, strong evidence for the first observation of a benzylic sulphide $\mathrm{Br}_{2}$ adduct in solution.

After 1 hour, signals assigned to bromide $4 \mathbf{e}$ were visible, with further conversion to $4 \mathrm{e}$ being very slow at $-20{ }^{\circ} \mathrm{C} .{ }^{34} \mathrm{We}$ thus raised the temperature of the experiment to $20{ }^{\circ} \mathrm{C}$ and continued monitoring the progress of the reaction for a further 14.5 hours, and observed that $1 \mathrm{e} \cdot \mathrm{Br}_{2}$ progressively converted to bromide 4e (Fig. 4). Repeating this experiment at $20^{\circ} \mathrm{C}$ for $60 \mathrm{~h}$ showed conversion of $\mathbf{1 e} \cdot \mathrm{Br}_{2}$ to $4 \mathrm{e}$ slowing markedly down to $87 \%$ after approximately 48 hours (see the $\mathrm{ESI} \dagger$ for spectra). It is important to note that the actual bromination of $\mathbf{1 e}$ was carried out at double the concentration $(0.33 \mathrm{M})$ requiring $48 \mathrm{~h}$ for complete conversion to $4 \mathbf{e}$.

The reaction of $\mathbf{1 e}$ also showed the formation of a side product observed with experiments at $-20{ }^{\circ} \mathrm{C}$ and $20{ }^{\circ} \mathrm{C}$, which started to form after the appearance of bromide 4e. This side product was proposed as being sulphide 1eb derived from the para bromination of the SPh group in 1e (Fig. 4), which was confirmed after comparison with an authentic sample. In an 


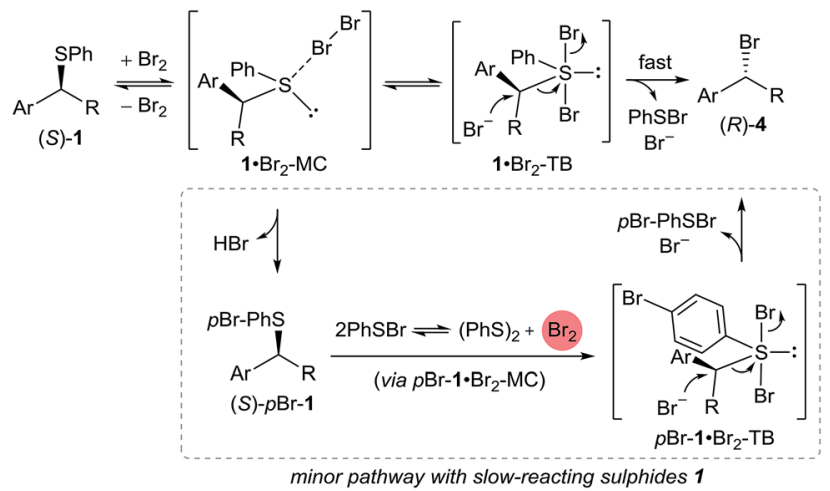

Scheme 5 Proposed mechanism taking into account stereochemical and NMR evidence, as well as side-product formation.

NMR experiment conducted at $20{ }^{\circ} \mathrm{C}$, sulphide $1 \mathrm{eb}$ converted cleanly to bromide $4 \mathbf{e}$ upon addition of 1.0 equivalent of $\mathrm{Br}_{2}$ (see the ESI $\uparrow$ for spectra). However, the bromination was slower than that with sulphide 1e, stopping at $82 \%$ conversion after $60 \mathrm{~h}$, with complete conversion reached only after a further addition of 0.2 equivalents of $\mathrm{Br}_{2}$.

A preliminary mechanistic picture is emerging from the above NMR experiments (Scheme 5). We propose that the addition of $\mathrm{Br}_{2}$ to sulphide $(S)-\mathbf{1}$ results in the formation of sulphur(II) adduct $1 \cdot \mathrm{Br}_{2}$-MC. Based on the facts that (i) $\mathrm{PhSBr}$ is formed as a by-product and (ii) 1 equivalent of bromide ions must be generated from $\mathrm{Br}_{2}$ for $\mathrm{S}_{\mathrm{N}} 2 \mathrm{C}-\mathrm{Br}$ bond formation to occur, we propose that $1 \cdot \mathrm{Br}_{2}-\mathrm{MC}$ must be in equilibrium with trigonal bipyramidal sulphur(Iv) dibromosulphurane intermediate $\mathbf{1} \cdot \mathrm{Br}_{2}$-TB. ${ }^{15}$ However, due to its high reactivity, it is very likely that $\mathbf{1} \cdot \mathrm{Br}_{2}$ - $\mathrm{TB}$ is present in very low concentrations. Invertive bromide ion attack on $1 \cdot \mathrm{Br}_{2}-\mathrm{TB}$ produces bromide $(R)-4$ with concomitant release of $\mathrm{PhSBr}$ and one equivalent of bromide ions. Therefore, only catalytic amounts of bromide ions are required to initiate the reaction. Bromide ions could be derived from the ionisation of $1 \cdot \mathrm{Br}_{2}$ - $\mathrm{TB}$ to form, in equilibrium, trigonal pyramidal bromosulphonium bromide $[1-\mathrm{Br}] \mathrm{Br}$. The fact that the reaction is significantly faster in coordinating MeCN (Table 1, entry 7) supports such a hypothesis. $^{35}$

As seen with sulphide 1e, slow-reacting sulphides can form the para-brominated side product $(S)$ - $p \mathrm{Br}-\mathbf{1}$, presumably via reaction with generated $\mathbf{1} \cdot \mathrm{Br}_{2}$-TB or possibly $\mathrm{PhSBr}_{3}$ formed in situ (in equilibrium) from the generated $\mathrm{PhSBr}$ and $\mathrm{Br}_{2}$ from 1. $\mathrm{Br}_{2}-\mathrm{MC}^{36}$ The exclusive para bromination of activated aromatics with bromodimethylsulphonium bromide has been reported. ${ }^{17 \boldsymbol{b}}$ Under optimised reaction conditions, the reductive coupling of two $\mathrm{PhSBr}$ molecules generates one molecule of $\mathrm{Br}_{2}$ that could oxidatively brominate $(S)-p \mathrm{Br}-\mathbf{1}$ in an analogous manner to $(S)-\mathbf{1}$ (Scheme 5). ${ }^{37}$

Finally, a pathway involving $\mathrm{n} \rightarrow \sigma^{*}$ type activation of the $\mathrm{C}-\mathrm{S}$ bond in $\mathbf{1} \cdot \mathrm{Br}_{2}$-MC towards bromide ion attack cannot be ruled out at present, ${ }^{38}$ and will be the subject of a detailed mechanistic analysis in the future.

\section{Conclusions}

We have disclosed a novel nucleophilic bromination reaction that employs easily accessible alkyl aryl sulphides as starting materials and basic elemental $\mathrm{Br}_{2}$ as an oxidative brominating agent. Reaction conditions are exceptionally mild, allowing the isolation of otherwise difficult to access and highly versatile benzylic $\beta$-bromo esters and nitriles in generally good to excellent yields. The reaction tolerates various functionalities and, remarkably, proceeds in the presence of protic functionalities such as alkyl acids and alcohols; a transformation incompatible with the vast majority of deoxybromination procedures. Optically active benzylic $\beta$-sulphido esters could be converted into the corresponding inverted $\beta$-bromo esters with high stereoselectivities. These bromides are configurationally stable at $-20{ }^{\circ} \mathrm{C}$, which should pave the way for their exploitation as highly useful chiral synthons in organic and medicinal chemistry. Their utility was demonstrated by the preparation of $\gamma$ azido alcohol $(S)-\mathbf{5}$, an advanced intermediate en route to dapoxetine, in $90 \%$ ee. The developed one-pot sequence from bromo ester $(R)-4 a$, consisting of a DIBAL ester reduction in the presence of a benzylic bromide and subsequent invertive nucleophilic azidation, proceeded with high stereochemical fidelity. Significantly, the required stereochemistry was introduced into sulphide precursor (S)-1a via an asymmetric sulphaMichael reaction, thus bypassing the dependency on optically active benzylic alcohols.

Low temperature NMR spectroscopic studies pointed to an initial MC adduct formation between the starting sulphide and $\mathrm{Br}_{2}$ en route to the bromide product. This was observed for adducts $1 \mathrm{a} \cdot \mathrm{Br}_{2}$ and $\mathbf{1 e} \cdot \mathrm{Br}_{2}$, with the latter, derived from slowreacting sulphide $1 \mathrm{e}$, being sufficiently stable at $-20{ }^{\circ} \mathrm{C}$ to allow its full characterisation. Subsequent stereoinvertive $\mathrm{C}-\mathrm{Br}$ bond formation is postulated to occur from the highly reactive isomeric dibromosulphurane $\mathrm{TB}$ adduct, proposed to be present in equilibrium with the MC adduct.

Given the very recent progress made in the synthesis of enantiomerically enriched benzylic aryl sulphides, ${ }^{39}$ we anticipate that the nucleophilic desulphurative bromination reported herein will find wide utility in the synthesis of optically active benzylic bromides relevant to drug discovery, agrochemicals, and materials.

Conceptually, the in situ oxidative activation of sulphides towards $\mathrm{S}_{\mathrm{N}} 2$ nucleophilic substitution should provide a platform for the development of other $\mathrm{C}-\mathrm{X}$ and $\mathrm{C}-\mathrm{C}$ bond forming reactions, and could prove to be a general, practical and viable alternative to oxygen based leaving groups.

\section{Conflicts of interest}

There are no conflicts to declare.

\section{Acknowledgements}

This work was supported by IRC (grants GOIPG/2015/3942 and EPSPG/2016/185 to D. C. and C. F.), the H2020 Programme (MSCA-RISE Halo 734361) and the Enterprise-Ireland CF Fund 
(CF20144034). We thank Dr Gary Hessman (TCD) for HRMS analysis.

\section{Notes and references}

1 For example, see: (a) A. H. Cherney, N. T. Kadunce and S. E. Reisman, Chem. Rev., 2015, 137, 11562; (b) S. L. Zultanski and G. C. Fu, J. Am. Chem. Soc., 2013, 135, 624; (c) C. Li, Y. Zhang, Q. Sun, T. Gu, H. Peng and W. Tang, J. Am. Chem. Soc., 2016, 138, 10774; (d) X. Wang, S. Wang, W. Xue and H. Gong, J. Am. Chem. Soc., 2015, 137, 11562; (e) A. López-Pérez, J. Adrio and J. C. Carretero, Org. Lett., 2009, 11, 5514 and references therein; $(f)$ X. Wang, G. Ma, Y. Peng, C. E. Pitsch, B. J. Moll, T. D. Ly, X. Wang and H. Gong, J. Am. Chem. Soc., 2018, 140, 14490; (g) X. Lu, Y. Wang, B. Zhang, J.-J. Pi, X.-X. Wang, T.-J. Gong, B. Xiao and Y. Fu, J. Am. Chem. Soc., 2017, 139, 12632.

2 For recent examples, see: (a) A. S. Dudnik and G. C. Fu, J. Am. Chem. Soc., 2012, 134, 10693; (b) C. K. Chu, Y. Liang and G. C. Fu, J. Am. Chem. Soc., 2016, 138, 6404; (c) D. M. Peacock, C. B. Roos and J. F. Hartwig, ACS Cent. Sci., 2016, 2, 647.

3 (a) W.-J. Chung and C. D. Vanderwal, Angew. Chem., Int. Ed., 2016, 55, 4396; (b) G. W. Gribble, Mar. Drugs, 2015, 13, 4044.

4 For a recent method via $\mathrm{C}-\mathrm{H}$ bromination, see: S. Sathyamoorthi, S. Banerjee, J. Du Bois, N. Z. Burns and R. N. Zare, Chem. Sci., 2018, 9, 100 and references therein.

5 R. Bohlmann, in Comprehensive Organic Transformations, ed. R. C. Larock, Wiley-VCH, New York, 2nd edn, 1999, pp. 689702.

6 (a) C. Dai, J. M. R. Narayanam and C. R. J. Stephenson, Nat. Chem., 2011, 3, 140; (b) T. V. Nguyen and A. Bekensir, Org. Lett., 2014, 16, 1720; (c) J. P. Moerdyk and C. W. Bielawski, Chem.-Eur. J., 2014, 20, 13487; (d) L. De Luca, G. Giacomelli and A. Porcheddu, Org. Lett., 2002, 4, 553.

7 (a) J. Chen, J.-H. Lin and J.-C. Xiao, Org. Lett., 2018, 20, 3061 and references therein; (b) J.-R. Dormoy, B. Castro and T. P. Bobinski, Triphenylphosphine Dibromide, in e-EROS, 2018, DOI: 10.1002/047084289X.rt370.pub2; (c) B. P. Mundy and C. A. Stewart, Phosphorus(III) Bromide, in e-EROS, 2008, DOI: 10.1002/047084289x.rp154.pub2.

8 (a) R. M. Denton, J. An, B. Adeniran, A. J. Blake, W. Lewis and A. M. Poulton, J. Org. Chem., 2011, 76, 6749; (b) H. A. van Kalkeren, S. H. Leenders, C. R. Hommersom, F. P. Rutjes and F. L. van Delft, Chem.-Eur. J., 2011, 17, 11290; (c) H. A. van Kalkeren, F. P. Rutjes and F. L. van Delft, Pure Appl. Chem., 2013, 86, 817.

9 (a) J. An, R. M. Denton, T. H. Lambert and E. D. Nacsa, Org. Biomol. Chem., 2014, 12, 2993; (b) C. M. Vanos and T. H. Lambert, Angew. Chem., Int. Ed., 2011, 50, 12222; (c) P. H. Huy, S. Motsch and S. M. Kappler, Angew. Chem., Int. Ed., 2016, 55, 10145; (d) T. Stach, J. Dräger and P. H. Huy, Org. Lett., 2018, 20, 2980.

10 (a) R. O. Hutchins, D. Masilamani and C. A. Maryanoff, J. Org. Chem., 1976, 41, 1071; (b) R. Stein, R. D. Dawe and J. R. Sweet, Can. J. Chem., 1985, 63, 3442; (c) Y. Chen,
W. L. Tang, J. Mou and Z. Li, Angew. Chem., Int. Ed., 2010, 49, 5278.

11 D. Canestrari, S. Lancianesi, E. Badiolaý, C. Strinna, H. Ibrahim and M. F. A. Adamo, Org. Lett., 2017, 19, 918.

12 (a) T. Zincke and W. Frohneberg, Ber. Dtsch. Chem. Ges., 1910, 43, 837; (b) H. Meerwein, K. F. Zenner and R. Gipp, Justus Liebigs Ann. Chem., 1965, 688, 67.

13 (a) H. F. Askew, P. N. Gates and A. S. Muir, J. Raman Spectrosc., 1991, 22, 265; (b) H. Böhme and E. Boll, Z. Anorg. Allg. Chem., 1957, 290, 17.

14 (a) G. Allegra, G. E. Wilson, E. Benedetti, C. Pedone and R. Albert, J. Am. Chem. Soc., 1970, 92, 4002 and references therein; ; (b) H. Bock, Z. Havlas, A. Rauschenbach, C. Näther and M. Kleine, Chem. Commun., 1996, 1529; (c) B. Regelmann, K. W. Klinkhammer and A. Schmidt, $Z$. Anorg. Allg. Chem., 1997, 623, 1633.

15 (a) W. Nakanishi, S. Hayashi, H. Tukada and H. Iwamura, J. Phys. Org. Chem., 1990, 3, 358; (b) A. Tanioku, T. Nakai, S. Hayashi and W. Nakanishi, Heteroat. Chem., 2011, 22, 446. 16 (a) S. A. Snyder and D. S. Treitler, Angew. Chem., Int. Ed., 2009, 48, 7899; (b) A. P. Brucks, S.-A. Treitler, D. S. Liu and S. A. Snyder, Synthesis, 2013, 45, 1886.

17 For examples on the reactivity of bromodimethylsulphonium bromide (BDMB), see: (a) L. H. Choudhury, Synlett, 2006, 1619; (b) G. A. Olah, L. Ohannesian and M. Arvanaghi, Synthesis, 1986, 868; (c) A. T. Khan, M. A. Ali, P. Goswami and L. H. Choudhury, J. Org. Chem., 2006, 71, 8961; (d) G. A. Olah, M. Arvanaghi and Y. D. Vankar, Synthesis, 1979, 721.

18 (a) E. F. Perozzi and J. C. Martin, J. Am. Chem. Soc., 1972, 94, 5519; (b) G. W. Astrologes and J. C. Martin, J. Am. Chem. Soc., 1977, 99, 4400.

19 (a) J. C. Martin, R. J. Arhart, J. A. Franz, E. F. Perozzi and L. J. Kaplan, Org. Synth., 1988, 6, 163; (b) S. S. Pooppanal, Synlett, 2009, 850.

20 For example, see: J. Drabowicz, W. Midura and M. Mikołajczyk, Synthesis, 1979, 39.

$21 \mathrm{PhICl}_{2}$ dissolved in chlorinated solvents precipitates upon cooling. For example, see: H. J. Lucas, E. R. Kennedy and M. W. Formo, Org. Synth., 1955, 3, 483.

22 In comparison, the crude material from the deoxybromination of methyl 3-hydroxy-3-phenylpropanoate with $\mathrm{PPh}_{3} / \mathrm{CBr}_{4}$ under Appel conditions contained 18\% alkene $\mathbf{3 a}$.

23 For applications of $\beta$-chloronitriles, see for example: T. J. Senter, M. C. O'Reilly, K. M. Chong, G. A. Sulikowski and C. W. Lindsley, Tetrahedron Lett., 2015, 56, 1276.

24 For chlorodehydration, see: (a) U. Münch and W. Pfleiderer, Helv. Chim. Acta, 2001, 84, 1504; (b) T. N. Majid, M. C. P. Yeh and P. Knochel, Tetrahedron Lett., 1989, 30, 5069.

25 B. Chen, C. Fang, P. Liu and J. M. Ready, Angew. Chem., Int. Ed., 2017, 56, 8780.

26 R. J. Van Hoveln, S. C. Schmid, M. Tretbar, C. T. Buttke and J. M. Schomaker, Chem. Sci., 2014, 5, 4763.

27 X. Fang, J. Li and C.-J. Wang, Org. Lett., 2013, 15, 3448.

28 V. V. Thankur, M. D. Nikalje and A. Sudalai, Tetrahedron: Asymmetry, 2003, 14, 581. This paper reported the 
synthesis of the corresponding optically active bromo ethyl ester $(S)$-4da from the alcohol precursor by deoxybromination with $\mathrm{PBr}_{3}$. In our hands, the crude material from this procedure (racemic alcohol) gave a mixture containing $c a .42 \%$ 4da (see the ESI $\dagger$ ).

29 Enantiomerically enriched bromo alcohol 4t $(21 \%$ ee) racemised completely within a few days: A. Isleyen, C. Tanyeli and O. Dogan, Tetrahedron: Asymmetry, 2006, 17, 1561.

30 The $(R)-5$ enantiomer is literature known: K. Sahasrabudhe, V. Gracias, K. Furness, B. T. Smith, C. E. Katz, D. S. Reddy and J. Aube, J. Am. Chem. Soc., 2003, 125, 7914.

31 K. Venkatesan and K. V. Srinivasan, ARKIVOC, 2008, XVI, 302 , and references therein.

32 M. Cartwright and A. A. Woolf, J. Fluorine Chem., 1981, 19, 101.

33 (a) N. C. Baenziger, R. E. Buckles, R. J. Maner and T. D. Simpson, J. Am. Chem. Soc., 1969, 91, 5749; (b) G. E. Wilson Jr and M. M. Y. Chang, J. Am. Chem. Soc., 1974, 96, 7533.
34 An NMR experiment ran at $-20{ }^{\circ} \mathrm{C}$ showed $8 \%$ conversion to 4e after 10 hours. See the ESI† for further information.

$35 \mathrm{HBr}$ generated from the para bromination of the SPh group in slow-reacting substrates is unlikely the source of bromide ions, because with sulphide 1e, side-product sulphide 1eb appears after initial formation of 4e. Furthermore, sulphide 1eb undergoes clean bromination to $4 \mathbf{e}$.

36 T. G. Back, S. Collins and M. V. Krishna, Can. J. Chem., 1987, 65, 38.

37 For reductive self-coupling of PhSX, see for example: (a) Q. Wu, D. Zhao, X. Qin, J. Lan and J. You, Chem. Commun., 2011, 47, 9188; (b) G. W. Kabalka, M. S. Reddy and M.-L. Yao, Tetrahedron Lett., 2009, 50, 7340; (c) G. A. Olah, S. C. Narang, L. D. Field and R. Karpeles, J. Org. Chem., 1981, 46, 2408.

38 W. Nakanishi, S. Hayashi and H. Kihara, J. Org. Chem., 1999, 64, 2630.

39 G. Liu, Z. Han, X.-Q. Dong and X. Zhang, Org. Lett., 2018, 20, 5636 and references therein. 